une revue Gallia

Rhône-Alpes | 2008

\title{
Charpentes de toit et de plafond de la vallée du Rhône méridionale (Ardèche-Drôme)
}

\section{Émilien Bouticourt}

\section{(2) OpenEdition \\ Journals}

Édition électronique

URL : http://journals.openedition.org/adlfi/1904

ISSN : 2114-0502

Éditeur

Ministère de la Culture

Référence électronique

Émilien Bouticourt, «Charpentes de toit et de plafond de la vallée du Rhône méridionale (Ardèche-

Drôme) ", ADLFI. Archéologie de la France - Informations [En ligne], Rhône-Alpes, mis en ligne le 01 mars 2008, consulté le 14 novembre 2019. URL : http://journals.openedition.org/adlfi/1904

Ce document a été généré automatiquement le 14 novembre 2019.

(c) Ministère de la Culture et de la Communication, CNRS 


\title{
Charpentes de toit et de plafond de la vallée du Rhône méridionale (Ardèche-Drôme)
}

\author{
Émilien Bouticourt
}

Identifiant de l'opération archéologique : 9722

Date de l'opération : 2008 (PT)

1 En 2008, nous avons conduit un programme de recherche sur les charpentes de toit et de plafond médiévales du sud de l'Ardèche et de la Drôme rhodanienne. Notre objectif principal était de réaliser un inventaire de ces structures et de mener à bien plusieurs études ciblées. Ce travail s'inscrit dans un cadre géographique plus vaste qui embrasse la région Provence-Alpes Côte-d'Azur (Vaucluse, Bouches-du-Rhône) et la région Languedoc-Roussillon (Gard). Les vestiges sont circonscrits sur une aire géographique limitrophe au Rhône. Ce choix émane d'un constat qui, une fois énoncé, pose question. Le territoire est marqué par l'absence de bois d'œuvre de qualité ce qui impose à l'industrie charpentière d'avoir recours à du bois d'importation transporté par flottage sur le Rhône. L'hypothèse est donc d'évaluer s'il se dégage sur ce long territoire des spécificités en matière de construction en bois. Le savoir-faire technique est-il semblable? Y a-il eu des échanges? Le travail décoratif des pièces de bois est-il comparable? Les essences de bois utilisées sont-elles les mêmes ? Ou au contraire les structures charpentées apparaissent-elles avec des spécificités locales très marquées s'inscrivant contre notre constat de départ: absence de bois d'œuvre localement et bois d'importation.

Dans cet espace du sud de la région Rhône-Alpes, plusieurs vestiges médiévaux ont été identifiés. Les structures les plus significatives ont fait l'objet d'une analyse archéologique accompagnée de relevés graphiques et photographiques. L'étude « bois à bois » des structures permet de mieux comprendre le savoir-faire des charpentiers (assemblage, technique de mise en œuvre) mais aussi de mieux qualifier la provenance 
des essences qui ont été utilisées. À cet égard, le travail de collaboration établi depuis plusieurs années avec Frédéric Guibal (Institut méditerranéen d'Écologie et de Paléoécologie - UMR 6116 CNRS), est particulièrement fructueux. Ainsi le croisement systématique des données de terrain, des données textuelles et les résultats issus des analyses dendrochronologiques permet d'inscrire ces vestiges dans le corpus des charpentes du sud de la France. Ce corpus offre la possibilité de dégager quelques grands types de charpente parfois fort éloignés des typologies établies pour le nord de la France.

3 Ainsi, l'usage de la technique de la ferme-diaphragme, déjà analysée dans les départements du Vaucluse et du Gard, a pu être reconnu dans de nouveaux exemples, notamment la chapelle Saint-Sornin de Serrières et l'ancienne église de Saint-Jean-deMuzols en Ardèche. Cette technique fut aussi en usage pour la réalisation des toitures des maisons urbaines comme au 10 de la rue du Portail à Châteauneuf-du-Rhône ou les avant-toits de la maison de la rue des Fontaines à Taulignan dans la Drome. Une attention particulière a également été portée à la technique de la poutre armée dont on trouve des exemples mis en œuvre dans le château du Bosquet à Saint-Martin d'Ardèche et dans l'ancien Palais des Évêques à Bourg-Saint-Andéol. Nous avons ainsi pu poursuivre et approfondir nos travaux sur cette technique médiévale méconnue. (Fig. $\mathrm{n}^{\circ} 1$ : Avant-toits de la maison de la rue des Fontaines à Taulignan (26))

Les résultats de l'année 2008 étendent sans conteste nos connaissances sur la question des charpentes dans le sud de la France. Ils viennent nourrir notre travail de doctorat, ils intègrent plusieurs publications en cours et ils sont présentés lors de colloques et programmes de recherche français et européens.

\section{ANNEXES}


Fig. $\mathrm{n}^{\circ} 1$ : Avant-toits de la maison de la rue des Fontaines à Taulignan (26)

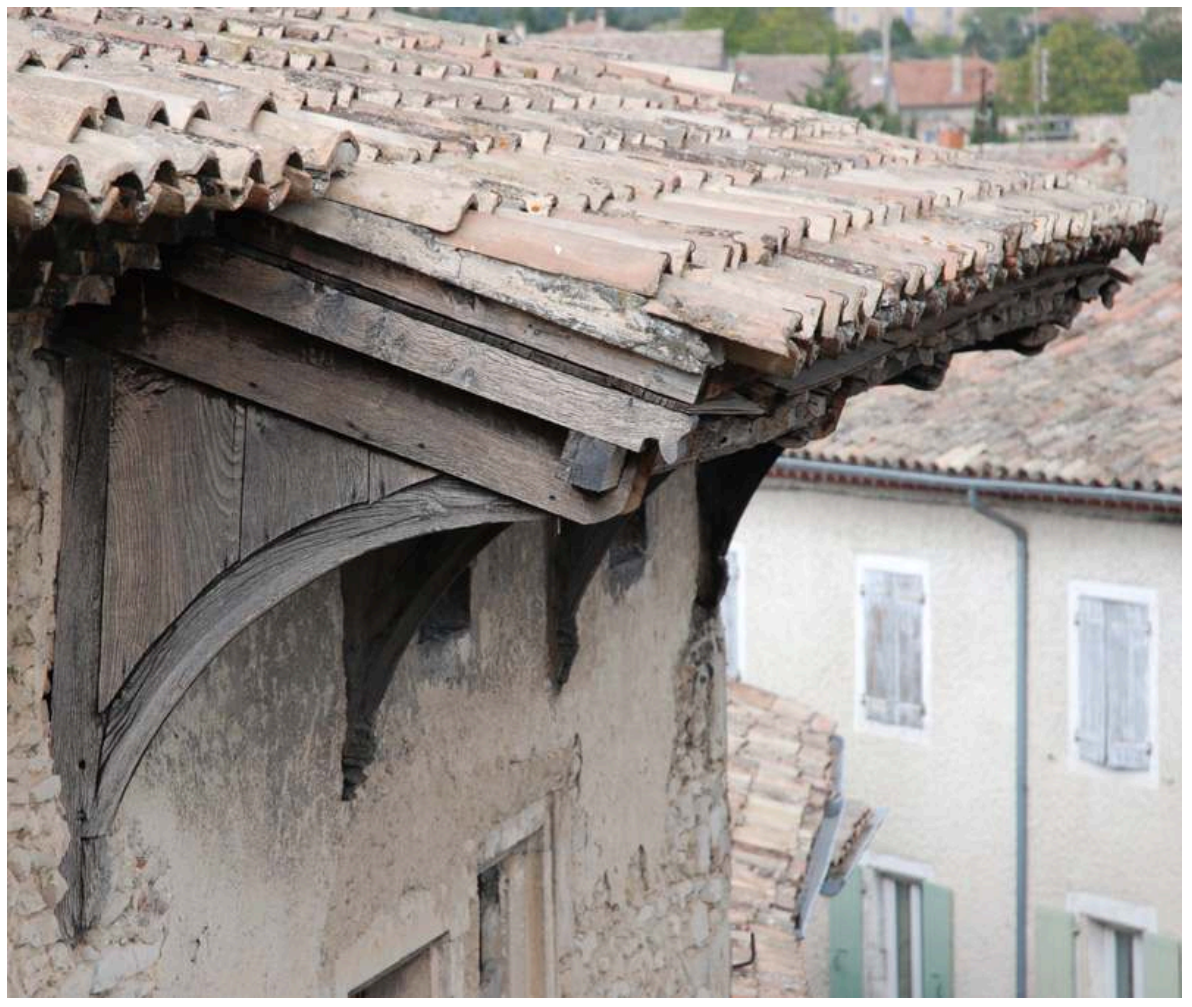

Auteur(s) : Bouticourt, E. Crédits : Bouticourt (2008)

\section{INDEX}

Index géographique : Rhône-Alpes, Ardèche (07)

Thèmes : charpente

Index chronologique : Moyen Âge

operation Prospection thématique (PRT)

\section{AUTEUR}

\section{ÉMILIEN BOUTICOURT}

étudiant 